\title{
Association between Serum Levels of Nitric Oxide and Hydrogen Sulfide in Pre-eclampsia
}

\author{
Chaudhuri S ${ }^{1}$, Banerjee $\mathrm{S}^{2}$, Kumar $\mathrm{A}^{3}$, Biswas $\mathrm{UK}^{4 *}$ \\ ${ }^{1}$ Department of Biochemistry, IPGMER, Kolkata, West Bengal, India; ${ }^{2}$ Department of GEOO, IPGMER, Kolkata, West Bengal, India; \\ ${ }^{3}$ Department of Biochemistry, Jagannath Gupta Institute of Medical Sciences, Kolkata, West Bengal, India; ${ }^{4}$ Department of Biochemistry, \\ North Bengal Medical College, Darjeeling, West Bengal, India
}

\begin{abstract}
Background: Preeclampsia is a multisystem disorder that is characterized by hypertension and proteinuria in women with no history of hypertension and proteinuria. It is mainly caused due to an imbalance between the physiological vasoconstrictor and vasodilator molecules. Nitric oxide and hydrogen sulphide are well established vasodilatory endogenous gasotransmitters that exhibit reduced production from intrauterine tissues during preeclampsia.

Aims and objectives: The aim of the study was to determine the serum levels of nitric oxide and hydrogen sulfide in preeclampsia cases compared with age matched controls and to rule out, whether there is a significant relationship if any, between these two gasotransmitters in preeclampsia.

Materials and methods: Serum levels of $\mathrm{NOx}$ and $\mathrm{H}_{2} \mathrm{~S}$ were measured in 100 pregnant women with preeclampsia and the values were matched with controls.

Results: The mean serum NOx levels of preeclamptic patients was $45.88 \pm 17.72 \mu \mathrm{mol} / \mathrm{L}$ which were significantly lower $(\mathrm{p}<0.001)$ than those observed in control with a values of $161.09 \pm 27.46 \mu \mathrm{mol} / \mathrm{L}$. The mean serum $\mathrm{H}_{2} \mathrm{~S}$ level was $32.31 \pm 12.62 \mu \mathrm{mol} / \mathrm{L}$ in patients which was significantly lower $(\mathrm{p}<0.001)$ when compared to control where mean we observed $114.50 \pm 20.35 \mu \mathrm{mol} / \mathrm{L}$. A positive correlation exists between serum $\mathrm{NOx}$ and $\mathrm{H}_{2} \mathrm{~S}$ levels in preeclampsia $(\mathrm{r}=0.691, \mathrm{p}<0.001)$.

Conclusion: The present study has elucidated that the serum levels of nitric oxide and hydrogen sulfide decrease in preeclampsia compared to normal pregnant women and these two molecules show a positive correlation in their levels in preeclampsia.
\end{abstract}

Keywords: Nirtic oxide; Hydrogen sulfide; Pre-eclampsia; Pregnant women

\section{INTRODUCTION}

Preeclampsia is a human pregnancy specific multisystem disease of unknown etiology that is defined by the onset of hypertension $(\mathrm{BP} \geq 140 / 90 \mathrm{mmHg}$ ) and newly detected proteinuria ( $\geq 300 \mathrm{mg}$ in 24 hours urinary collection), at a period of $>20$ weeks of gestation in a previously normotensive and non proteinuric women [1]. Preeclampsia is an important public health problem both in developing and developed countries contributing to maternal and fetal morbidity and mortality.

Preeclampsia occurs mainly due to the abnormal cytotrophoblastic invasion into the spiral arteries, uteroplacental hypoperfusion, an imbalance between increased synthesis of vasoconstrictors and decreased production of vasodilators, increased oxidative stress and endothelial dysfunction [2,3].

In normal pregnancy, nitric oxide $(\mathrm{NO})$ is produced endogenously from L-arginine and a molecule of oxygen by endothelial nitric oxide synthase (eNOS) in intrauterine tissues and it helps to maintain the vascular tone to increase uterine blood flow to ensure adequate delivery of oxygen and nutrients to the growing fetus [4]. Endothelium-dependent vasodilatation is mediated partly by NO and is also upregulated by the increased estrogen level in normal pregnancy [5].

Despite extensive research in this area, the role of nitric oxide in preeclampsia in dubious with respect to its variable plasma levels reported in various research studies.

Correspondence to: Biswas UK, Department of Biochemistry, North Bengal Medical College, Darjeeling, West Bengal, India, Tel: +91-9051642109; E-mail: bdrutpalkumar@rediffmail.com

Received: May 09, 2019; Accepted: June 28, 2019; Published: July 05, 2019

Citation: Chaudhuri S, Banerjee S, Kumar A, Biswas UK (2019) Association between Serum Levels of Nitric Oxide and Hydrogen Sulfide in Preeclampsia. Biochem Anal Biochem 8:384. doi: 10.35248/2161-1009.19.8.384.

Copyright: ( 2019 Chaudhuri S, et al. This is an open-access article distributed under the terms of the Creative Commons Attribution License, which permits unrestricted use, distribution, and reproduction in any medium, provided the original author and source are credited. 
Hydrogen sulfide is a gasotransmitter that is produced endogenously in mammalian tissues from L-cysteine mainly by an enzymatic pathway with 3 enzymes: cystathionine beta synthetase (CBS), cystathionine gamma lyase (CSE) and 3-mercaptopyruvate sulfur transferase (3-MST) [6-8].

Non enzymatic production of $\mathrm{H}_{2} \mathrm{~S}$ occurs through glucose, glutathione, inorganic and organic polysulfides (present in garlic) and elemental sulfur.

In the past few years some studies have shown the expression of CBS and CSE enzymes in human intrauterine tissues and placenta $[9,10]$ and have demonstrated that $\mathrm{H}_{2} \mathrm{~S}$ produced endogenously by these enzymes play a vital role in maintaining uterine contractility during pregnancy and labor [10]. In a report from recent study, it was observed that CBS mRNA expression was significantly down regulated in placental villous tissue obtained from pregnant mothers suffering from early onset preeclampsia [7]. Another study demonstrated that down regulation of $\mathrm{CSE} / \mathrm{H}_{2} \mathrm{~S}$ activity contributed to the pathogenesis of maternal hypertension and placental abnormalities in preeclampsia [11].

The biochemical interactions of $\mathrm{NO}$ and $\mathrm{H}_{2} \mathrm{~S}$ is complicated and currently unclear. Some studies have reported $\mathrm{NO}$ and $\mathrm{H}_{2} \mathrm{~S}$ positively stimulate each other's production and function [12,13] whereas, other studies have demonstrated opposite findings [14,15]. $\mathrm{H}_{2} \mathrm{~S}$ and NO mediated vascular remodeling function occur through a common signaling pathway that includes VEGF, HIF-1 $\alpha$, PI3K/ AKT. PI3K/AKT induces the activity of eNOS and thus increases $\mathrm{NO}$ production. $\mathrm{H}_{2} \mathrm{~S}$ also has been reported to prevent eNOS degradation and induce eNOS phosphorylation with subsequent NO production via PI3K/Akt activity and p38 MAPK pathways. The role of $\mathrm{NO}$ as a potent vasodilatory gasotransmitter, through activation of soluble guanylate cyclase (sGC) and subsequent cGMP production is well documented. Similarly $\mathrm{H}_{2} \mathrm{~S}$ can exhibit vasodilatory effects indirectly by delaying cGMP degeneration through PDE5 (phosphodiesterase-5) inhibition [16]. Thus, NO and $\mathrm{H}_{2} \mathrm{~S}$ increase cGMP production that has downstream signaling effects of endothelial cell migration, proliferation and angiogenesis through PKG/Ras-Raf/ERK-p38 MAPK pathway [17]. A recent study by Kida et al. showed that $\mathrm{NaHS}$, a $\mathrm{H}_{2} \mathrm{~S}$ donor, increases $\mathrm{NO}$ production in cultured endothelial cells by inducing endothelial nitric oxide synthase [18]. In yet another research conducted by Coletta et al. established that hydrogen sulphide and nitric oxide are mutually dependent in their role in regulation of angiogenesis and endothelium dependent vasorelaxation [19].

Thus, this study was aimed to determine the levels of nitric oxide and hydrogen sulfide in preeclampsia cases and compare them with normal pregnant women. The study was designed to elucidate if any correlation exists between these two gasotransmitters that might contribute to the pathogenesis of preeclampsia.

\section{MATERIALS AND METHODS}

This is a non-interventional, observational, cross-sectional hospital based study, conducted in the Department of Biochemistry and Obstetrics and Gynecology, I.P.G.M.E\&R, Kolkata, India.

The Inclusion criteria of the subjects included diagnosed preeclampsia that is, those presenting with blood pressure $\geq 140 / 90$ $\mathrm{mm} \mathrm{Hg}$ and proteinuria $\geq 300 \mathrm{mg} / 24$ hours or protein creatinine ratio $\geq 0.3$, appearing after 20 weeks of gestation up to 12 weeks postpartum. A total of 100 pregnant women with were included as cases based on these inclusion criteria. One hundred normal healthy pregnant women after 20 weeks of gestation were included as controls.

The Exclusion criteria of the study were pregnant women with previously diagnosed hypertension before conception or before 20 weeks of gestation and pregnancy with gestational diabetes mellitus and other complications like cardiovascular, neurological, autoimmune disorders or malignancy were excluded from the study.

Fasting blood samples were collected from cases and controls under aseptic conditions after obtaining informed consent.

\section{Ethical clearance and approval}

All tests and procedures performed in this study involving human subjects were in accordance with the ethical standards of the institutional and national research committee and with the 1975 revised Helsinki declaration and its later amendments and other comparable ethical standards.

\section{Laboratory analysis}

The collected blood samples were centrifuged at $3500 \mathrm{rpm}$ for 30 minutes to obtain the serum. The serum and urine samples were stored at -20 degrees Centigrade for further analysis.

Nitric oxide in serum was measured as NOx (nitrates plus nitrites) as $\mathrm{NO}_{2}$ and $\mathrm{NO}_{3}$ represent the end products of $\mathrm{NO}$ oxidation in blood and NOx measurement reflects the systemic NO production. The nitrite levels were measured by Griess reaction and the nitrate was measured after reduction with cadmium catalyst to nitrite, followed by Griess reaction.

Serum levels of $\mathrm{H}_{2} \mathrm{~S}$ were estimated by a spectrophotometric method that involved the reaction of sulfide with N,N-dimethylp-phenylenediamine sulfate in the presence of oxidizing agent $\mathrm{Fe}^{3+}$ in hydrochloric acid to form methylene blue whose absorbance was read at $670 \mathrm{~nm}$.

\section{Statistical analysis}

The data analysis of this study is done by the statistical software Minitab Version-2018. All the data are expressed in mean \pm SD. Comparison of data is done by unpaired Student's t- test and Pearson's correlation. The p-value $<0.05$ was considered as statistically significant.

\section{RESULTS}

The clinical and biochemical variables of the study subjects are depicted in Table 1.

The mean serum NOx levels of preeclamptic patients is 45.88 $\pm 17.72 \mu \mathrm{mol} / \mathrm{L}$ which is significantly lower $(\mathrm{p}-<0.001)$ when compared with controls is $161.09 \pm 27.46 \mu \mathrm{mol} / \mathrm{L}$ as shown in Figure 1.

The mean serum $\mathrm{H}_{2} \mathrm{~S}$ level is $32.31 \pm 12.62 \mu \mathrm{mol} / \mathrm{L}$ in patients while it is significantly lower $(\mathrm{p}<0.001)$ when compared with controls where mean was $114.50 \pm 20.35 \mu \mathrm{mol} / \mathrm{L}$ as shown in Figure 2.

The scatter diagrams plotted between serum $\mathrm{H}_{2} \mathrm{~S}$ and serum $\mathrm{NOx}$ levels in preeclampsia cases in Figure 3, shows a positive correlation. The Pearson's correlation coefficient $r$ is 0.691 and the results are statistically significant with a p-value $<0.001$. 
Table 1: The clinical and biochemical parameters of the study subjects.

\begin{tabular}{|c|c|c|c|}
\hline Variables & Patients $(n=100)$ mean & Controls $(n=100)$ mean & p-Value (with 95\% C.I.) \\
\hline Age (y) & $25.51 \pm 4.03$ & $24.52 \pm 3.54$ & 0.166 (NS) \\
\hline Height $(\mathrm{cm})$ & $159.45 \pm 7.13$ & $160.2 \pm 6.42$ & 0.683 (NS) \\
\hline Weight (kg) & $76.43 \pm 8.95$ & $72.07 \pm 8.28$ & $<0.001^{*}$ \\
\hline $\mathrm{SBP}(\mathrm{mm} \mathrm{Hg})$ & $148.74 \pm 7.01$ & $123.48 \pm 7.88$ & $<0.001^{*}$ \\
\hline $\mathrm{DBP}(\mathrm{mm} \mathrm{Hg})$ & $99.9 \pm 6.6$ & $78.86 \pm 5.32$ & $<0.001^{*}$ \\
\hline Serum $\mathrm{H}_{2} \mathrm{~S}(\mu \mathrm{mol} / \mathrm{L})$ & $32.31 \pm 12.62$ & $114.50 \pm 20.35$ & $<0.001^{*}$ \\
\hline Serum NOx $(\mu \mathrm{mol} / \mathrm{L})$ & $45.88 \pm 17.72$ & $161.09 \pm 27.46$ & $<0.001^{*}$ \\
\hline
\end{tabular}

${ }^{*}$ T-test done, $\mathrm{p}<0.05$ is considered significant.

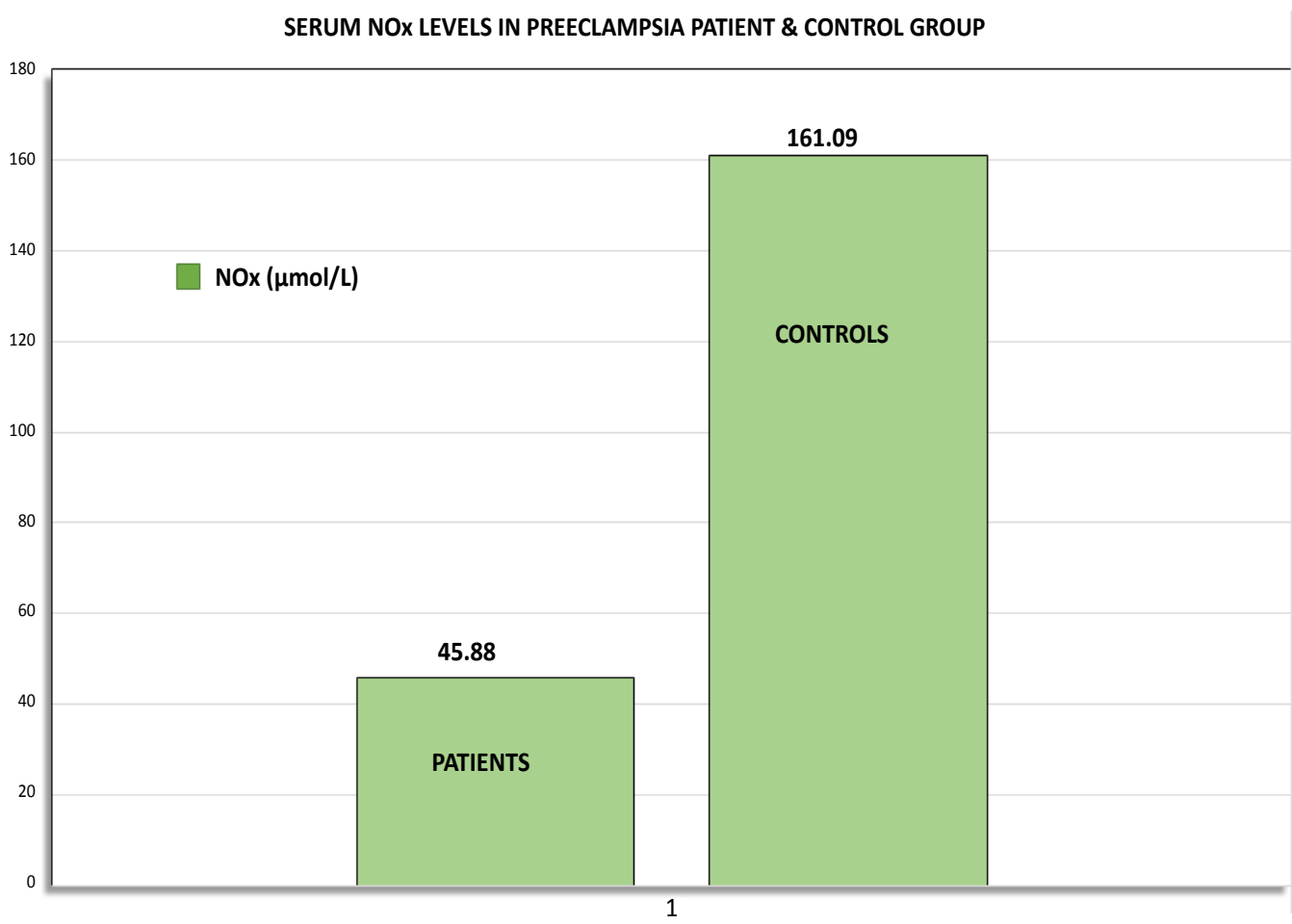

Figure 1: Comparison of serum NOx levels in cases and controls.

SERUM $\mathrm{H}_{2}$ S LEVEL IN PREECLAMPSIA PATIENT AND CONTROL GROUP

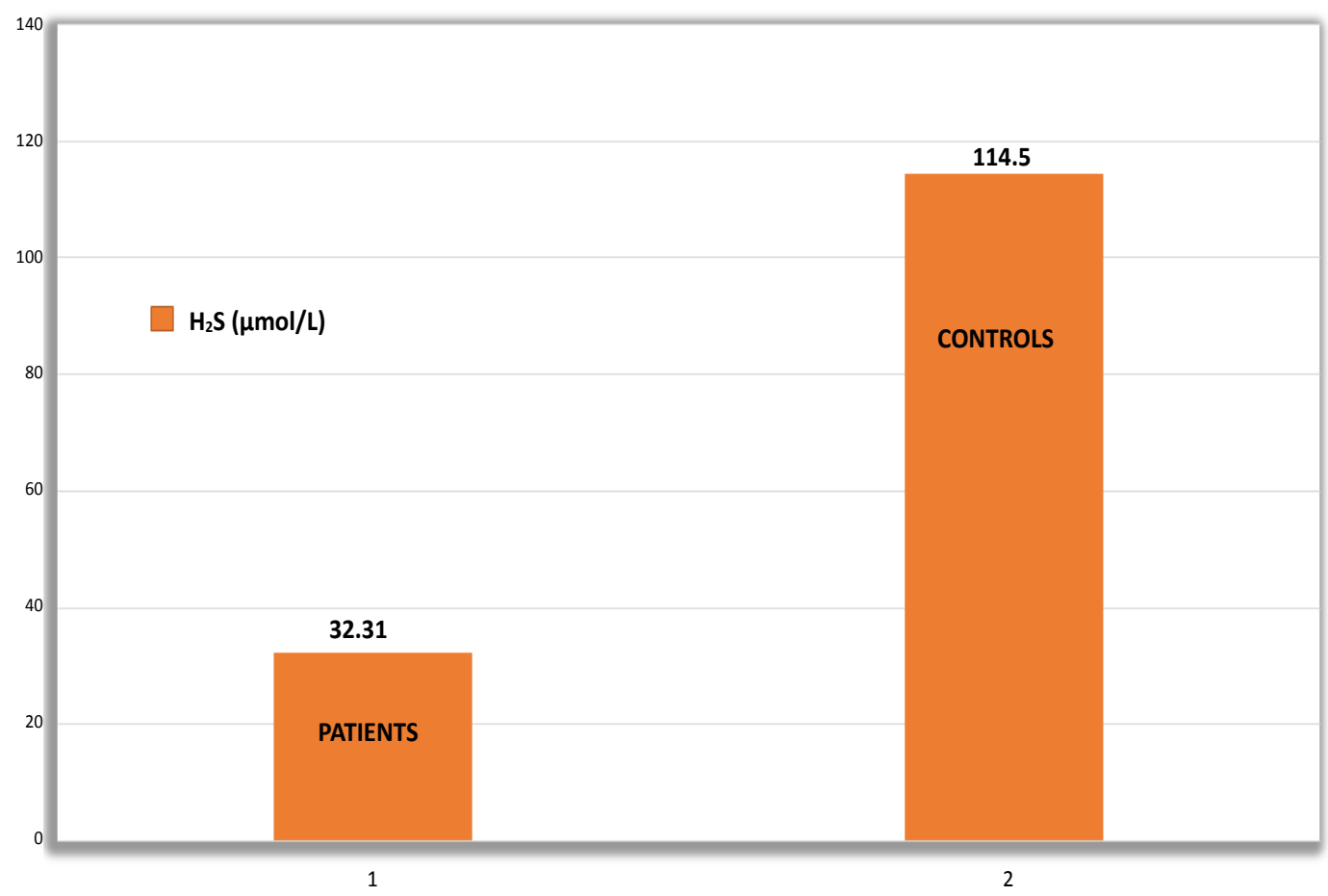

Figure 2: Comparison of serum $\mathrm{H}_{2} \mathrm{~S}$ levels in cases and controls. 
In Figure 4, a scatter diagram plotted between serum $\mathrm{H}_{2} \mathrm{~S}$ and serum NOx levels in controls, also shows a positive correlation with Pearson's correlation coefficient of 0.718 and the result is statistically significant with a p-value $<0.001$.

This implicates that there is a fall in serum nitric oxide levels, there is a simultaneous reduction in serum hydrogen sulphide levels and there exists a negative correlation between the levels of these two gasotransmitters and the blood pressure, in both cases and controls.

\section{DISCUSSION}

Preeclampsia is a human pregnancy specific disorder that is chiefly manifested as hypertension whose main cause is an imbalance between the vasodilators and vasoconstrictors in the circulation. There is a deficient synthesis of vasodilatory molecules like nitric oxide [20] and prostacyclin $\left(\mathrm{PGI}_{2}\right)[20,21]$. On the other hand, there is increased production of vasoconstrictor molecules like endothelin 1, thromboxane $A_{2}$, IL-6, angiotensin-II, TNF- $\alpha$ and other cytokines from the vascular endothelial cells and activated leucocytes [21-23]. The final response to all these stimuli is endothelial dysfunction and vasospasm and elevation of arterial blood pressure.

Hydrogen sulphide and nitric oxide have been established as the two important vasodilatory gasotransmitters present in the circulation of all human beings.

Previous studies had shown that $\mathrm{H}_{2} \mathrm{~S}$ producing enzyme, cystathionine-Y-lyase, normally produced from the placenta, had depressed activity in pregnancies complicated with hypertension and placental abnormalities and this in turn resulted in decreased $\mathrm{H}_{2} \mathrm{~S}$ levels in the peripheral circulation (11). The endothelium derived NO produced by eNOS has been found to play an

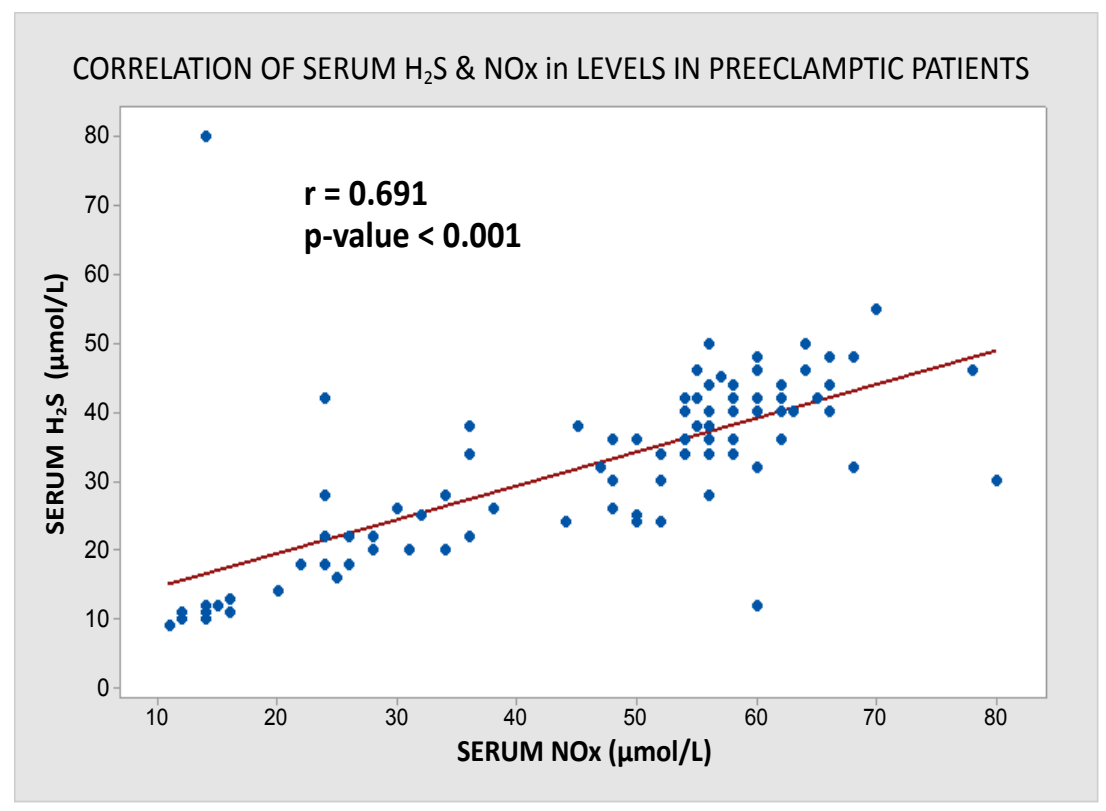

Pearson's Correlation done.p-value $<0.05$ considered significant.

Figure 3: Correlation between serum levels of $\mathrm{NOx}$ and $\mathrm{H}_{2} \mathrm{~S}$ in cases.

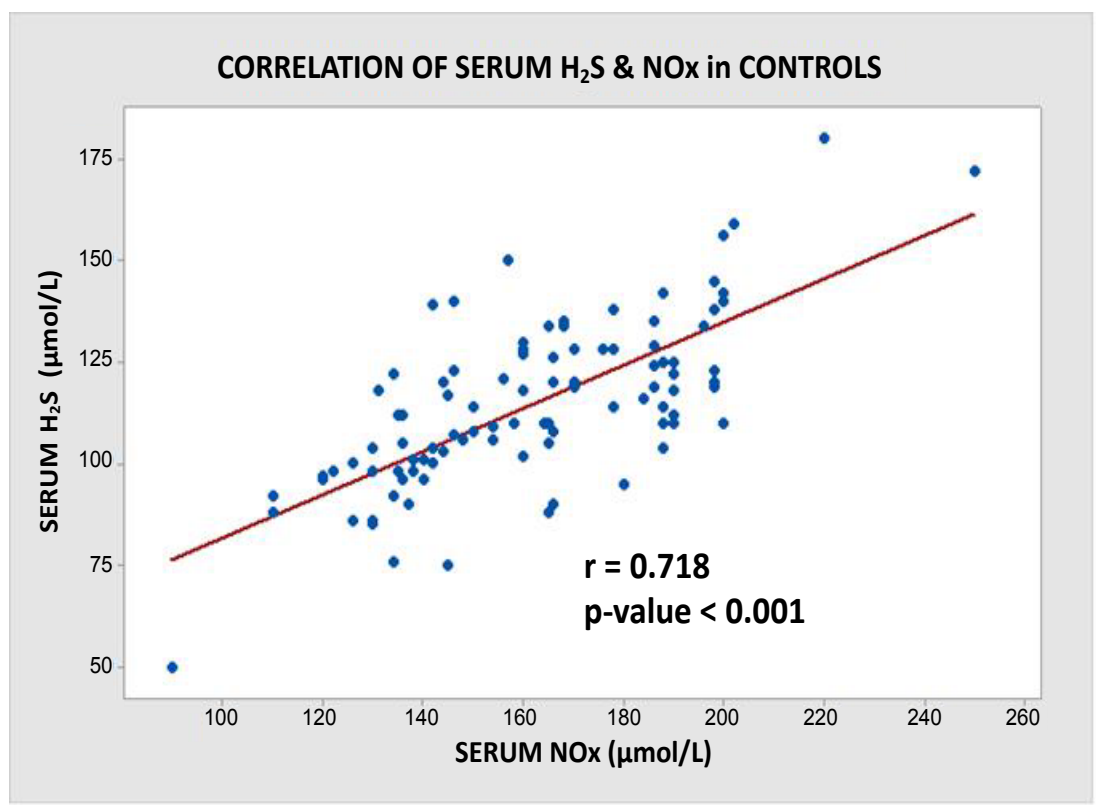

Pearson's Correlation done.p-value $<0.05$ considered significant.

Figure 4: Correlation between serum levels of $\mathrm{NOx}$ and $\mathrm{H}_{2} \mathrm{~S}$ in controls. 
important role in the maintenance of vascular tone in preeclampsia and hypertension [24]. In previous studies the eNOS-derived NO was seen to maintain the circulatory homeostasis through vascular smooth muscle relaxation for increased uterine blood flow [25] and uterine myometrial quiescence [26]. Some studies reported that the plasma levels of nitric oxide were found to decrease in pre-eclampsia. Still the role of NO in preeclampsia is not clear as studies have also reported the high levels of $\mathrm{NO}$ in preeclampsia as a marker of oxidative stress [27].

Reports from the recent studies have linked with both $\mathrm{NO}$ and $\mathrm{H}_{2} \mathrm{~S}$ working as a common signaling pathway in a cohesive manner and synergistically maintain the normal vascular tone [17].

Still there exists a significant amount of uncertainty regarding the biochemical interactions of $\mathrm{NO}$ and $\mathrm{H}_{2} \mathrm{~S}$ and their subsequent physiological effects. Some studies have shown that $\mathrm{NO}$ and $\mathrm{H}_{2} \mathrm{~S}$ positively stimulate each other's production and function [12,13] whereas, other studies have demonstrated opposite findings $[14,15]$.

Some experimental evidence suggests that nitric oxide (NO) and hydrogen sulfide $\left(\mathrm{H}_{2} \mathrm{~S}\right)$ signaling pathways are closely interlinked, with mutual attenuation or potentiation of biological responses in the cardiovascular and other physiological systems.

Studies demonstrate a common signaling pathway exist where NO$\mathrm{H}_{2} \mathrm{~S}$ crosstalk mediates their effects on vascular functions such as vasodilation, vascular remodeling and angiogenesis [13,28,29].

In 2015, Cortess-Krott et al. performed an experimental study and found that at physiological $\mathrm{pH}, \mathrm{NO}$ and sulfide form a network of cascading chemical reactions that generate radical intermediates and anionic and uncharged solutes, resulting in accumulation of three major products: nitrosopersulfide (SSNO), polysulfides, and dinitrososulfite [N-nitrosohydroxylamineN-sulfonate (SULFI/ $\mathrm{NO})$ ], each with a distinct chemical biology and in vitro and in vivo bioactivity [30]. These anionic products scavenge, transport, and produce $\mathrm{NO} / \mathrm{HNO}$ or sulfide/sulfane sulfur. These observations provided a chemical foundation for the cross-talk between the $\mathrm{NO}$ and $\mathrm{H}_{2} \mathrm{~S}$ signaling pathways in biology and suggested that the biological actions of these molecules can be neither considered nor studied in isolation.

$\mathrm{H}_{2} \mathrm{~S}$ and $\mathrm{NO}$ mediated vascular remodeling function occur through a common pathway that includes VEGF, HIF-1 $\alpha$, PI3K/ AKT. PI3K/AKT induces the activity of eNOS and thus increases $\mathrm{NO}$ production. $\mathrm{H}_{2} \mathrm{~S}$ also has been reported to prevent eNOS degradation and induce eNOS phosphorylation with subsequent NO production via PI3K/Akt activity and p38 MAPK pathways.

$\mathrm{H}_{2} \mathrm{~S}$ therapy is beneficial for ischemic vascular remodeling in eNOS $\%$ mice where hydrogen sulphide stimulates non-enzymatic generation of nitric oxide via xanthine oxidase $(\mathrm{XO})$ mediated nitrite reduction that increases tissue VEGF, cGMP production and angiogenesis activity under ischemic conditions [28].

The role of $\mathrm{NO}$ as a potent vasodilatory gasotransmitter, through activation of soluble guanylate cyclase (sGC) and subsequent cGMP production, is well established. Similarly $\mathrm{H}_{2} \mathrm{~S}$ can exhibit vasodilatory effects indirectly by delaying cGMP degeneration through PDE5 (phosphodiesterase-5) inhibition [16].

Studies with knockout mice with deletion of NOS or CSE further prove the vasodilatory roles of $\mathrm{NO} / \mathrm{H}_{2} \mathrm{~S}$ signaling pathway $[31,32]$.

A recent study by Kida et al. showed that $\mathrm{NaHS}$, a $\mathrm{H}_{2} \mathrm{~S}$ donor, increases $\mathrm{NO}$ production in cultured endothelial cells by inducing endothelial nitric oxide synthase. NaHS was found to increase the intracellular calcium concentration. This effect of NaHS was inhibited in the presence of calcium chelators. This study thus established that $\mathrm{H}_{2} \mathrm{~S}$ acts directly on the endothelial cells and stimulates $\mathrm{NO}$ production by activating eNOS and by releasing intracellular calcium in the endoplasmic reticulum, it eventually causes vasodilatation [18].

In a research conducted by Coletta et al. it was found that hydrogen sulphide and nitric oxide are mutually dependent in their role in regulation of angiogenesis and endothelium dependent vasorelaxation. It was found that inhibition of eNOS activity by chemical mediators, attenuated the vasodilatory effect of hydrogen sulphide, which proved that $\mathrm{NO}$ has some role in $\mathrm{H}_{2} \mathrm{~S}$ signaling pathway. Conversely, the chemical inhibition of $\mathrm{H}_{2} \mathrm{~S}$ producing enzyme cystathionine gamma lyase (CSE), inhibited NO mediated vasodilation and angiogenesis [19]. Thus this experimental study illustrated that $\mathrm{NO}$ and $\mathrm{H}_{2} \mathrm{~S}$ significantly influence each other's biological action by some common signaling pathway.

But further studies are required to fill this lacuna in understanding the complex interrelationship between the biological actions of these two endogenous gasotransmitters. This will definitely help to elucidate the significant potential of their interaction in various physiological and pathological processes.

\section{CONCLUSION}

The present study elucidates a significant reduction in the bioavailability of both these gasotransmitters, $\mathrm{NOx}$ and $\mathrm{H}_{2} \mathrm{~S}$ in preeclampsia compared to normal pregnant women. This study also for the first time reveals a positive correlation between these two endogenously produced vasodilator molecules, $\mathrm{NOx}$ and $\mathrm{H}_{2} \mathrm{~S}$ in preeclampsia.

This implies that these two vasodilatory molecules, $\mathrm{NO}$ and $\mathrm{H}_{2} \mathrm{~S}$ in the circulation work in harmony with each other with the aim to maintain the normal vascular tone. Thus, it may be deduced that the decreased synthesis of both $\mathrm{H}_{2} \mathrm{~S}$ and $\mathrm{NO}$ from the intrauterine tissues in preeclampsia resulted in an imbalance that goes beyond the control of compensation and thus results in vasoconstriction and a rise in blood pressure.

Till today the only known most effective treatment of preeclampsia has been delivery to prevent further fetal and maternal complications because the placenta has been presumed to be the main factor responsible for the pathogenesis of this disorder.

The present study results showing the alterations in nitric oxide and hydrogen sulphide levels in pregnancy and preeclampsia, can be used as a base to research further into the treatment options for preeclampsia.

Hence, various therapy options which increase the levels of these two molecules in circulation like $\mathrm{NO}$ and $\mathrm{H}_{2} \mathrm{~S}$ donors can be of potential use in early prevention and treatment of this disorder of pregnancy.

But a further large-scale study in future in this direction may help to establish the preventive and curative roles of nitric oxide and hydrogen sulfide in preeclampsia.

\section{LIMITATIONS OF THE STUDY}

The sample size of the study is small and latest analytical methods should be incorporated for the measurement of $\mathrm{NOx}$ and $\mathrm{H}_{2} \mathrm{~S}$. 


\section{ACKNOWLEDGEMENTS}

I would like to express my heartfelt thanks and gratitude to my guide, Dr. Utpal Kumar Biswas, The then Professor of the Department of Biochemistry, IPGME\& R, Kolkata, for his immense support and patience in guiding me through my research work.

\section{REFERENCES}

1. Roberts JM, August PA, Bakris G, Barton JR, Bernstein IM, Druzin $\mathrm{M}$, et al. Hypertension in pregnancy. Report of the American College of Obstetricians and Gynecologists' Task Force on Hypertension in Pregnancy. Obstet Gynecol. 2013;122:1122-1131.

2. Uzan J, Carbonnel M, Piconne O, Asmar R, Ayoubi JM. Pre-eclampsia: pathophysiology, diagnosis, and management. Vasc Health Risk Manag. 2011;7:467-474.

3. Davison JM, Homuth V, Jeyabalan A, Conrad KP, Karumanchi SA, Quaggin S, et al. New Aspects in the Pathophysiology of Preeclampsia. J Am Soc Nephrol. 2004;15:2440-2448.

4. Choi JW, Im MW, Pai SH. Nitric Oxide Production Increases during Normal Pregnancy and Decreases in Preeclampsia. Ann Clin Lab Sci. 2002;32:257-263.

5. Sladek SM, Magness RR, Conrad KP. Nitric oxide and pregnancy. Am J Physiol. 1997;272:441-463.

6. Chen C, Xin H, Zhu Y. Hydrogen sulfide: third gaseous transmitter, but with great pharmacological potential. Acta Pharmacol Sin. 2007;28:1709-1716.

7. Holwerda KM, Bos EM, Rajakumar A, Ris-Stalpers C, Pampus MG van, Timmer A, et al. Hydrogen sulfide producing enzymes in pregnancy and preeclampsia. Placenta. 2012;33:518-521.

8. Kolluru GK, Shen X, Bir SC, Kevil CG. Hydrogen Sulfide Chemical Biology: Pathophysiological roles and detection. Nitric Oxide. 2013;35:5-20.

9. Patel P, Vatish M, Heptinstall J, Wang R, Carson RJ. The endogenous production of hydrogen sulphide in intrauterine tissues. Reprod Biol Endocrinol. 2009;7:10.

10. You XJ, Xu C, Lu JQ, Zhu XY, Gao L, Cui XR, et al. Expression of Cystathionine $\beta$-synthase and Cystathionine $\gamma$-lyase in Human Pregnant Myometrium and Their Roles in the Control of Uterine Contractility. PLoS One. 2011;6:e23788.

11. Wang K, Ahmad S, Cai M, Rennie J, Fujisawa T, Crispi F, et al. Dysregulation of Hydrogen Sulfide $\left(\mathrm{H}_{2} \mathrm{~S}\right)$ Producing Enzyme Cystathionine $\gamma$-lyase (CSE) Contributes to Maternal Hypertension and Placental Abnormalities in Preeclampsia. Circulation. 2013;127:2514-2522.

12. Kondo K, Bhushan S, King AL, Prabhu SD, Hamid T, Koenig S, et al. $\mathrm{H}_{2} \mathrm{~S}$ protects against pressure overload-induced heart failure via upregulation of endothelial nitric oxide synthase. Circulation. 2013;127:1116-1127.

13. Cai W-J, Wang M-J, Moore PK, Jin H-M, Yao T, Zhu YC. The novel proangiogenic effect of hydrogen sulfide is dependent on Akt phosphorylation. Cardiovasc Res. 2007;76:29-40.

14. Kubo S, Kurokawa Y, Doe I, Masuko T, Sekiguchi F, Kawabata A. Hydrogen sulfide inhibits activity of three isoforms of recombinant nitric oxide synthase. Toxicology 2007;241:92-97.

15. Prathapasinghe GA, Siow YL, Xu Z. Inhibition of cystathionine-" synthase activity during renal ischemia reperfusion: role of $\mathrm{pH}$ and nitric oxide. Am J Physiol Renal Physiol. 2008;295: 912-922.
16. Bucci M, Papapetropoulos A, Vellecco V, Zhou Z, Pyriochou A, Roussos C, et al. Hydrogen sulfide is an endogenous inhibitor of phosphodiesterase activity. Arterioscler Thromb Vasc Biol 2010;30:1998-2004.

17. Kolluru GK, Shen X, Kevil CG. Tale of two gases: NO and $\mathrm{H}_{2} \mathrm{~S}$, foes or friends for life? Sci Direct. 2013;1:313-318.

18. Kida M, Sugiyama T, Yoshimoto T, Ogawa Y. Hydrogen sulfide increases nitric oxide production with calcium-dependent activation of endothelial nitric oxide synthase in endothelial cells. Eur J Pharm Sci. 2013;48:211-215.

19. Coletta C, Papapetropoulos A, Erdelyi K, Olah G, Módis K, Panopoulos $\mathrm{P}$, et al. Hydrogen sulfide and nitric oxide are mutually dependent in the regulation of angiogenesis and endotheliumdependent vasorelaxation. Proc Natl Acad Sci USA. 2012;109:91619166.

20. Hladunewich M, Karumanchi SA, Lafayette R. Pathophysiology of the Clinical Manifestations of Preeclampsia. Clin J Am Soc Nephrol. 2007;2:543-549.

21. Konar H. DC Dutta's Textbook of Obstetrics. JP Medical Ltd. 2014.

22. Schipper E-JI, Bolte AC, Schalkwijk CG, Van Geijn HP, Dekker GA. TNF-receptor levels in preeclampsia results of a longitudinal study in high-risk women. J Matern Fetal Neonatal Med. 2005;18:283-287.

23. Maynard SE, Venkatesha S, Thadhani R, Karumanchi SA. Soluble Fms-like tyrosine kinase 1 and endothelial dysfunction in the pathogenesis of preeclampsia. Pediatr Res. 2005;57:1-7.

24. Nobunaga T, Tokugawa Y, Hashimoto K, Kimura T, Matsuzaki N, Nitta Y, et al. Plasma nitric oxide levels in pregnant patients with preeclampsia and essential hypertension. Gynecol Obstet Invest. 1996;41:189-193.

25. Cindrova-Davies T. The therapeutic potential of antioxidants, ER chaperones, $\mathrm{NO}$ and $\mathrm{H}_{2} \mathrm{~S}$ donors, and statins for treatment of preeclampsia. Front Pharmacol. 2014.

26. Ekerhovd E, Norström A. Involvement of a nitric oxide-cyclic guanosine monophosphate pathway in control of Fallopian tube contractility. Gynecol Endocrinol. 2004;19:239-246.

27. Matsubara K, Higaki T, Matsubara Y, Nawa A. Nitric Oxide and Reactive Oxygen Species in the Pathogenesis of Preeclampsia. Int J Mol Sci. 2015;16:4600-4614.

28. Bir SC, Kolluru GK, McCarthy P, Shen X, Pardue S, Pattillo CB, et al. Hydrogen sulfide stimulates ischemic vascular remodeling through nitric oxide synthase and nitrite reduction activity regulating hypoxiainducible factor- $1 \alpha$ and vascular endothelial growth factor-dependent angiogenesis. J Am Heart Assoc. 2012;1:e004093.

29. Gu Q, Wang B, Zhang XF, Ma YP, Liu JD, Wang XZ. Contribution of hydrogen sulfide and nitric oxide to exercise-induced attenuation of aortic remodeling and improvement of endothelial function in spontaneously hypertensive rats. Mol Cell Biochem. 2013;375:199-206.

30. Cortese-Krott MM, Kuhnle GGC, Dyson A, Fernandez BO, Grman $\mathrm{M}$, DuMond JF, et al. Key bioactive reaction products of the $\mathrm{NO} / \mathrm{H}_{2} \mathrm{~S}$ interaction are S/N-hybrid species, polysulfides, and nitroxyl. Proc Natl Acad Sci USA. 2015;112:4651-4660.

31. Yang G, Wu L, Jiang B, Yang W, Qi J, Cao K, et al. $\mathrm{H}_{2} \mathrm{~S}$ as a physiologic vasorelaxant: hypertension in mice with deletion of cystathionine gamma-lyase. Sci. 2008;322:587-590.

32. Huang PL, Huang Z, Mashimo H, Bloch KD, Moskowitz MA, Bevan JA, et al. Hypertension in mice lacking the gene for endothelial nitric oxide synthase. Nature. 1995;377:239-242. 